\title{
Dynamic Hyaluronan drives liver endothelial cells towards angiogenesis
}

Sampa Ghose ${ }^{1,2^{*}}$ D, Subhrajit Biswas ${ }^{3 *}$, Kasturi Datta ${ }^{4}$ and Rakesh K. Tyagi ${ }^{2}$

\begin{abstract}
Background: Angiogenesis, the formation of new blood vessels from pre-existing vasculature is essential in a number of physiological processes such as embryonic development, wound healing as well as pathological conditions like, tumor growth and metastasis. Hyaluronic acid (HA), a high molecular weight polysaccharide, major component of extracellular matrix is known to associate with malignant phenotypes in melanomas and various other carcinomas. Hyaluronic acid binding protein 1 (HABP1) has been previously reported to trigger enhanced cellular proliferation in human liver cancer cells upon its over-expression. In the present study, we have identified the HA mediated cellular behaviour of liver endothelial cells during angiogenesis.

Methods: Endothelial cells have been isolated from perfused liver of mice. Cell proliferation was studied using microwell plates with tetrazole dye. Cell migration was evaluated by measuring endothelial monolayer wound repair as well as through transwell migration assay. Alterations in proteins and mRNA expression were estimated by immunobloting and quantitative real time PCR using Applied Biosystems. The paraformaldehyde fixed endothelial cells were used for immuno- florescence staining and F-actin detection with conjugated antibodies. The images were captured by using Olympus florescence microscope (IX71).

Results: We observed that administration of HA enhanced cell proliferation, adhesion, tubular sprout formation as well as migration of liver endothelial cells (ECs). The effect of HA in the rearrangement of the actins confirmed HA -mediated cytoskeleton re-organization and cell migration. Further, we confirmed enhanced expression of angiogenic factors like VEGF-A and VEGFR1 in endothelial cells upon HA treatment. HA supplementation led to elevated expression of HABP1 in murine endothelial cells. It was interesting to note that, although protein levels of $\beta$ - catenin remained unaltered, but translocation of this protein from membrane to nucleus was observed upon HA treatment, suggesting its role not only in vessel formation but also its involvement in angiogenesis signalling.

Conclusions: The elucidation of molecular mechanism (s) responsible for HA mediated regulation of endothelial cells and angiogenesis contributes not only to our understanding the mechanism of disease progression but also offer new avenues for therapeutic intervention.
\end{abstract}

Keywords: Hyaluronic acid or Hyaluronan, Liver endothelial cells, Angiogenesis

\footnotetext{
* Correspondence: sampaghose@gmail.com; sbiswas2@amity.edu

'Department of Medical Oncology, All India Institute of Medical Sciences,

Ansari Nagar, New Delhi 110029, India

${ }^{3}$ Amity Institute of Molecular Medicine and Stem Cell Research, Amity

University Uttar Pradesh (AUUP), Sector 125, NOIDA, Uttar Pradesh 201313,

India

Full list of author information is available at the end of the article
}

(c) The Author(s). 2018 Open Access This article is distributed under the terms of the Creative Commons Attribution 4.0 International License (http://creativecommons.org/licenses/by/4.0/), which permits unrestricted use, distribution, and reproduction in any medium, provided you give appropriate credit to the original author(s) and the source, provide a link to the Creative Commons license, and indicate if changes were made. The Creative Commons Public Domain Dedication waiver (http://creativecommons.org/publicdomain/zero/1.0/) applies to the data made available in this article, unless otherwise stated. 


\section{Background}

The metastatic spread of tumor cells is the most lethal aspect of cancer, which often occurs through enhanced vascularization. The initiation of angiogenesis embarks with the local release of pro- and anti-angiogenic growth factors by endothelial cells (ECs). Such release occurs in response to disease- or injury- induced inflammation. Vascular endothelial growth factors (VEGF) and glycosaminoglycans are important regulators [1]. The VEGFinduced cytoskeleton reorganization also plays a crucial role in the angiogenic processes [2, 3], though the intracellular signals leading to these events are not yet clear. A series of sequential events are involved in angiogenesis including local degradation of endothelial basement membrane by the action of proteases, formation of a lumen, proliferation and migration of endothelial cells that gives rise to a functional vessel.

The chief component of the extracellular matrix (ECM), hyaluronan or hyaluronic acid (HA) promotes tumor growth by providing a loose matrix for cancer cells to migrate and adhere [4]. Since long time, the polysaccharide $\mathrm{HA}$, has been used in a wide variety of medical fields as diverse as neurosurgery to cutaneous wound healing. HA is comprised of 10,000 repeating units of $(\beta, 1 \rightarrow 4)-D$ glucuronic acid- $(\beta, 1 \rightarrow 3)-\mathrm{N}$-acetyl-D-glucosamine [5], and its molecular weight ranges from $400 \mathrm{Da}$ to several MDa. Within the ECM the degraded fragments of HA, termed as low molecular weight hyaluronan (LMW-HA), have been reported as significant regulator of angiogenesis [6]. HA has also received great attention due to multi-functional regulation on related biological functions such as inflammation, wound healing and tumor growth [7]. Previously we identified the hyaladherin, the hyaluronic acid binding protein 1 (HABP1), from rat liver using HA-affinity column chromatography [8]. We have demonstrated for the first time, that Plasmodium falciparum infected RBCs use HABP1 as a receptor to bind to human endothelial cells [9]. Our studies have shown that overexpression of HABP1 in the human liver cell line HepG2 (HepR21) induces high endogenous glutathione level and enhanced cellular proliferation along with increased endogenous level of HA and intercellular HA cables [10] whereas HABP1 overexpression leads to ROS-mediated apoptosis in normal fibroblasts $[11,12]$. The elevated level of HA is associated with hyper-proliferative and invasive tumorigenesis [13, 14].

Several studies are emphasizing the involvement of $\mathrm{HA}$ in endothelial cell proliferation, migration and new vessel formation [15]. However, very few reports are available on the effect of HA on liver sinusoidal endothelium. In the liver, HA is synthesized mostly by the sinusoidal pericyte and the hepatic stellate cells (HSCs); while it is degraded by the liver sinusoidal endothelial cells (LSECs) [16]. The role of HABP1 in cell-adhesion is well established and in combination with HA, it facilitates the process of adhesion and de-adhesion during mitotic stages [10]. The another major adhesion molecule, $\beta$-catenin is not only one of the key molecules regulating the hepatic zonation pattern [17] but also acts as transcriptional co-regulator and an adaptor protein for cellular adhesion. Postnatal liver growth and development is also dependent on $\beta$-catenin activity. Extensive cell proliferation occurs in the liver after birth, in conjunction with a substantial increase in $\beta$-catenin protein and its nuclear translocation [18]. In fact liver metastasis is often supported by abnormal $\beta$-catenin expression and localization [19]. $\beta$-catenin accumulation within the nucleus or cytoplasm has been found remarkably in more than half of all cancers and is related to increased tumorigenicity [20]. The biological events that couple HA and $\beta$-catenin function to angiogenesis are still unknown.

The present study has focused on identification of HA mediated cellular behaviour of liver endothelial cells involving $\beta$-catenin activation and its influence on angiogenic signals for cellular adhesion and wound healing. We have worked on how HA stimulates endothelial cell migration and adhesion through VEGF, leading towards angiogenesis in vitro. The cellular roles of HA are perpetrated through molecular interactions with HA-binding proteins or hyaladherins. In particular, we have demonstrated here the role of the VEGF receptors involved in initiating the coordinated signals that leads to actin based motility and angiogenesis.

\section{Methods}

\section{Endothelial cell isolation and cell culture}

A reproducible method has been used to isolate endothelial cells (ECs) from murine liver as described earlier [21] with modifications. After sacrificing the mice, liver was perfused with warm PBS by injecting needle to flush out blood. The perfused liver was then put into serum-free media with antibiotics and minced into small pieces. Minced liver was incubated in 7-8 ml collagenase $(500 \mu \mathrm{g} / \mathrm{ml})$ for $15 \mathrm{~min}$. After spinning down at $2000 \mathrm{rpm}$ for $5 \mathrm{~min}$, supernatant was removed and the collagenase treatment was repeated for 2-3 times for total digestion of big chunks of tissues. Completely digested cells were re-suspended in complete media with $20 \%$ FBS, passed through $40 \mu \mathrm{m}$ filter and plated on a $0.1 \%$ gelatin coated plate. The cells were incubated for 3-4 h. Media was splashed directly into cells for a couple of rounds and washed extensively with serum-free media to wash off all other cell types except ECs. ECs were cultured on collagen-coated plates and grown in MCDB 131 (HiMedia) media supplemented with 20\% FBS, $100 \mu \mathrm{g} / \mathrm{ml}$ penicillin and $100 \mu \mathrm{g} / \mathrm{ml}$ streptomycin (complete medium). The cultures were maintained in a 
humidified incubator maintained at $5 \% \mathrm{CO}_{2}$ and $95 \%$ air atmosphere at $37{ }^{\circ} \mathrm{C}$. EC phenotype was confirmed by immuno-cytochemistry with anti- CD31 (Abcam) and anti-VEGF antibody (Thermo Fisher Scientific).

\section{Cell proliferation assay / MTT assay}

The low molecular weight hyaluronic acid from umbilical cord (LMW-HA) were purchased from Sigma-Aldrich and used to study its effect on ECs with final concentration of $10 \mu \mathrm{g} / \mathrm{ml}$ [22]. ECs were plated at a density of $2 \times 10^{4}$ cells/ well in 48-microwell plates and were treated with $\mathrm{HA}(10 \mu \mathrm{g} / \mathrm{ml})$ for $24-72 \mathrm{~h}$. At the indicated time points, cells were treated with $10 \mu \mathrm{l}$ yellow tetrazole dye [3-(4,5-Dimethylthiazol-2-yl)-2,5- diphenyl tetrazolium bromide], MTT $(1 \mathrm{mg} / \mathrm{ml}$; in PBS) for $4 \mathrm{~h}$ at $37^{\circ} \mathrm{C}$ in a dark, humidified, $5 \% \mathrm{CO}_{2}$ environment as per instructions from HiMedia (\#TC191) and our previously standardized protocol [23]. The precipitate formed was solubilised in $150 \mu$ isopropanol after discarding the media and then absorbance was recorded at $570 \mathrm{~nm}$ using a plate reader.

\section{Adhesion assay}

For both untreated and HA treated $(10 \mu \mathrm{g} / \mathrm{ml}$, for $48 \mathrm{~h}$ ) ECs, $1 \times 10^{5}$ cells were seeded in each well of a 48 well plate. Non-adherent cells were removed after 2 and 4 h by washing with PBS. Only adherent cells were fixed by treating with $1 \%$ glutaraldehyde for $10 \mathrm{~min}$ and stained with $0.1 \%(w / v)$ crystal violet (Sigma-Aldrich) for $25 \mathrm{~min}$. The cells were washed and solubilized in 1\% TritonX100 (Sigma-Aldrich) for overnight and the absorbance was measured at $620 \mathrm{~nm}$. Samples were taken in triplicates for each time point.

\section{Wound healing assay}

Endothelial migration was evaluated by measuring endothelial monolayer wound repair. The confluent monolayers of cells were scratched identically with the narrow edge of a $200 \mu \mathrm{l}$ tip. The monolayer was washed with serum-free media and treated with HA $(10 \mu \mathrm{g} / \mathrm{ml})$. ECs were observed at different time point to see the extent of wound healing. Some wells were kept untreated as control. DIC images were captured at the time of scratching and up to $48 \mathrm{~h}$ under an inverted phase contrast microscope.

\section{Tubule formation assay}

Vascular tubule formation assay was performed in a three-dimensional culture on top of growth factor reduced matrigel (Becton Dickinson). After the treatment, cells were trypsinized and seeded on solidified matrigel in 48 well plates. The vascular sprout or growing tubule structure was photographed from randomly selected fields after 18 and $42 \mathrm{~h}$ of HA treatment under the microscope. Untreated endothelial cells were used as control. Tubules were quantified per field for statistical validation.

\section{Migration assay}

Cell migration assay was performed using transwell plate (HiMedia). HA treated and untreated ECs were trypsinized and re-suspended in serum free MCDB131 media (HiMedia). 1 X10 $0^{5}$ cells were added in the upper chamber of transwells $(8.0 \mu \mathrm{m}) .500 \mu \mathrm{l}$ of MCDB131 media with $20 \%$ FBS (HiMedia) was added to the lower chamber of each well which act as a chemoattractant. The plate was covered and incubated at $37{ }^{\circ} \mathrm{C}$ in $5 \% \mathrm{CO}_{2}$ incubator for at least $24 \mathrm{~h}$. The cells on the lower surface of transwell membrane were fixed with $2 \%$ paraformaldehyde for 10 min followed by staining with $0.1 \%$ Crystal violet for $1 \mathrm{~h}$. The number of migrated cells were counted in five different fields under the microscope and represented in a histogram showing the average number of migrated cells through the porous transwell membrane.

\section{Immunoblot analysis}

Untreated and HA treated (24 and 48 h) ECs were lysed in RIPA buffer. Equal amounts of protein samples were electrophoresed by $10 \%$ SDS-PAGE. Following transfer into the PVDF membrane, proteins were immuno detected by probing the blot with specific antibodies. The bound antibody complexes were detected using enhanced chemi-luminescence (ECL) system.

\section{RNA isolation and qPCR}

Total RNA was isolated from untreated and HA treated endothelial cells $(10 \mu \mathrm{g} / \mathrm{ml}$ for 24 and $48 \mathrm{~h})$ using TRI reagent according to the manufacturer's instructions. RNA was quantitated and $5 \mu \mathrm{g}$ of total RNA was used for cDNA synthesis with the help of RevertAid H Minus First cDNA Synthesis Kit with random hexamers as primers (Thermo Scientific \#K1631). GAPDH, $\beta$-catenin, VEGF and VEGFR1 were amplified by PCR using $1 \mu \mathrm{l}$ of cDNA. Amplification of GAPDH gene was taken as a positive control. The PCR products were resolved on $1.5 \%$ agarose gel and visualized by ethidium bromide staining. qPCR was performed using the Eva Green PCR Master Mix (G-biosciences, cat \#786-858) and ABI Prism 7500 (Applied Biosystems). Amplification was done by denaturation for $10 \mathrm{~min}$ at $95{ }^{\circ} \mathrm{C}$ followed by 40 cycles of $15 \mathrm{~s}$ at $95^{\circ} \mathrm{C}, 30 \mathrm{~s}$ at $60{ }^{\circ} \mathrm{C}$ and $30 \mathrm{~s}$ at $72{ }^{\circ} \mathrm{C}$. Relative quantitation was done by parentizing threshold cycle $(C t)$ values of each sample gene with $C t$ values of GAPDH. $\triangle C t$ corresponds to the difference between the $C t$ of the genes of interest and the $C t$ of GAPDH [10]. Data are presented as fold changes of mRNAs, which were calculated for HA treated endothelial cells (derived from $2^{-\Delta \Delta c t}$ method) in comparison with untreated 
control samples. The primers were designed from NCBI (https://www.ncbi.nlm.nih.gov/tools/primer-blast/) and sequences are mentioned in Additional file 1: Table S1.

\section{Immuno-florescence staining and F-actin detection}

Endothelial cells were seeded on $0.1 \%$ gelatin coated cover slip and incubated for 4 to $5 \mathrm{~h}$ for attachment. Once the cells get attached, they were treated with $10 \mu \mathrm{g} / \mathrm{ml} \mathrm{HA}$. After $48 \mathrm{~h}$ of HA treatment, cells were fixed in $4 \%(v / v)$ paraformaldehyde in PBS for 20 min at room temperature. Cells were permeabilized using $0.1 \%$ TritonX-100 in PBS (v/v) for 5 min at room temperature and the excess detergent was washed off with PBS. Cells were blocked with 5\% BSA/PBS for $1 \mathrm{~h}$ at room temperature followed by incubation with primary antibody $(1: 1000)$ in $1 \%$ BSA/PBS for overnight at $4{ }^{\circ} \mathrm{C}$. Cells were washed thrice with PBS and then incubated with Cy3 tagged secondary antibody (Sigma) for $1 \mathrm{~h}$. Hoechst 33342 (Sigma) was co-incubated with the secondary antibody to visualize the nucleus. Cells were again washed with PBS thrice, $5 \mathrm{~min}$ each and mounted on $30 \%$ glycerol in PBS. To see actin organization, paraformaldehyde fixed cells were permeabilized and incubated with fluorophore-conjugated phalloidin along with hoechst for $1 \mathrm{~h}$. After incubation the cells were rinsed with PBS several times, mounted on 30\% glycerol and images were captured in a florescence microscope (Olympus IX71).

\section{Statistical analysis}

All data are presented as mean \pm S.D. (standard deviation) from at least three separate experiments. Student's $t$ test was applied to evaluate the differences between treated and control groups. Data from multiple groups were analysed by one-way ANOVA. For all the tests, the level of significance was kept at $p<0.05$.

\section{Results \\ Exogenous HA treatment induces proliferation of endothelial cells}

Within the liver, HA is mostly synthesized by the sinusoidal pericytes, the hepatic stellate cells (HSCs) [24, 25] and removed from circulation through degradation especially by liver sinusoidal endothelial cells (LSEC) $[26,27]$. Although HA can also be metabolized in vitro by cultured hepatocytes and Kupffer cells [28, 29], the role of these cells in the physiological HA metabolism in vivo was shown as minor importance in literature compared to LSEC. Here we explored the effect of exogenous HA on proliferation of liver ECs isolated from mice. We treated ECs with $10 \mu \mathrm{g} / \mathrm{ml} \mathrm{HA}$ upto $72 \mathrm{~h}$ and performed MTT assay at different mentioned time points. A positive impact of HA supplementation has been observed on EC proliferation (Fig. 1a). In fact ECs, treated with HA have significantly higher growth rate than untreated ECs, suggesting the probable constructive role of $\mathrm{HA}$ in liver microenvironment.

\section{Faster wound healing and improved cellular adhesion due to HA treatment}

The angiogenic response during chronic liver injury and cirrhosis are associated with formation of a dense neovasculature fibrotic septa surrounding regenerative nodules. In hepatocellular carcinoma (HCC), the intra-tumorous angiogenesis is accompanied by peri-tumorous angiogenesis in the adjacent liver tissue [30, 31]. HA stimulate angiogenesis and become extraordinarily active in pathological events [32]. These pathologic vessels become capillarized, defenestrated and form a more classic vascular basement membrane [33]. Liver endothelial cells in these circumstances take on an "activated" angiogenic phenotype which includes altered surface markers [34, 35] and changes in both morphology and behaviour [35], allowing not only increased proliferation but also invasion, adhesion and wound healing. Similar changes can be seen in the settings of portal hypertension [36], HCC [37] and during the aging process [38].

Here we assumed that there would be an association of HA uptake with endothelial cell migration and adhesion, two key events associated with angiogenesis. To elucidate the effects of HA on wound healing scratch assay was performed. The result showed that, higher number of HA treated endothelial cells migrated to the wounded area, leading to faster recovery of wound in comparison to the untreated cells (Fig. 1b \& c). Further, the result of migration assay performed using transwell membrane also corroborates the findings of wound healing assay (Fig. 1d). Therefore, both the date suggested that, cellular migration of ECs in vitro culture is significantly influenced by HA treatment. In addition, the effect of HA on cellular adhesion has also been verified. Adhesion assay for ECs was performed in presence or absence of HA in culture media. Interestingly, increased adhesion has been observed in HA treated ECs in comparison to untreated cells (Fig. 1e).

\section{Enhanced tubule formation in liver endothelial cells upon HA treatment}

Tumor induced angiogenesis requires migration and remodelling of endothelial cells derived from pre-existing blood vessels. Vascular endothelial growth factor (VEGF) is the most implicated growth factor in the development of neo-vessels. With a goal to explore whether HA treatment has any effect on tubule formation, we assessed the vascular network formation in a three-dimensional 

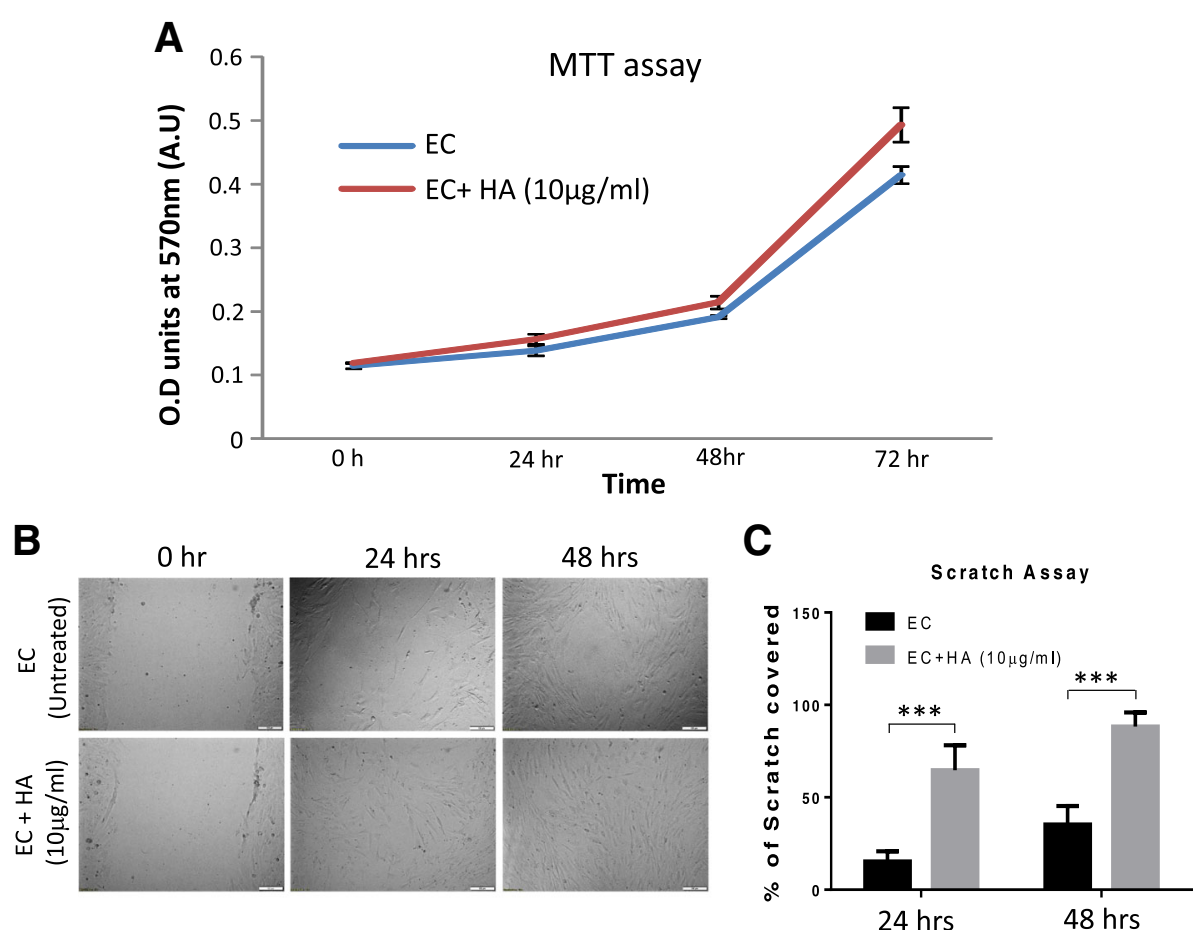

D Migration assay

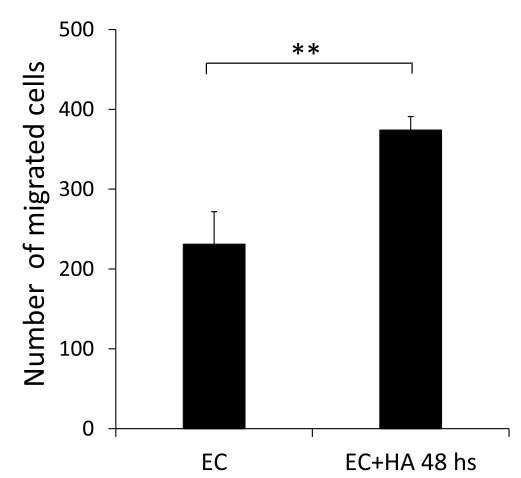

E Adhesion assay

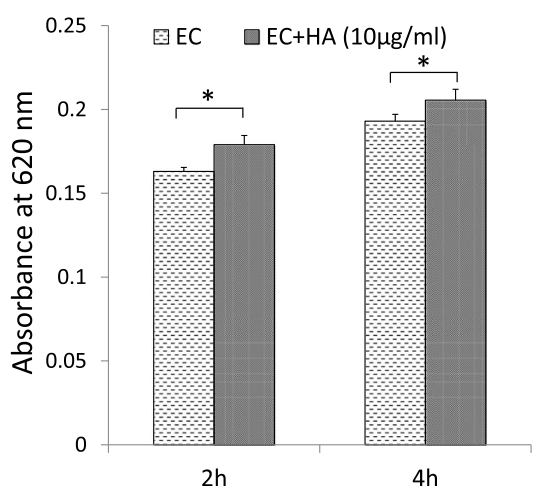

Fig. $1 \mathrm{HA}$ Influence the proliferation, wound healing, migration and adhesion of endothelial cells. a Cell survivability assay (MTT) was performed for untreated and HA-treated $(10 \mu \mathrm{g} / \mathrm{ml}) \mathrm{ECs}$ to examine the effect of HA on proliferation rate. Three wells for each condition were taken for different time points. Same number of cells were seeded in triplicates for each time point along with a set of untreated cells as controls $\mathbf{b}$ Images of scratch assay showing the influence of HA on ECs migration to recover the wound. Scale bar, $100 \mu \mathrm{m}$. c Percentage of scratch covered after HA treatment were quantified after 24 and $48 \mathrm{~h} \mathbf{d}$ Graph showing the number of migrated cells through the porous transwell membrane in untreated control and HA treated $(10 \mu \mathrm{g} / \mathrm{ml}$ for $48 \mathrm{~h}$ ) ECs. e Graph showing change of adhesion property of cells with $\mathrm{HA}$ treatment $(10 \mu \mathrm{g} / \mathrm{ml}$ for $48 \mathrm{~h}$ ) after 2 and $4 \mathrm{~h}$ in comparison to equal number of untreated control ECs. ${ }^{*} p<0.05 ;{ }^{* *} p<0.01,{ }^{* * *} p<0.001$

matrigel assay. In this assay, ECs were added on solidified matrigel and monitored for growth of tubules. The DIC pictures were taken for both HA treated and untreated ECs growing on matrigel at different time points. More number of vascular sprouts were appeared in case of the HA treated ECs as compared to untreated cells (Fig. 2a). Result was confirmed by quantifying the tubules per microscopic field (Fig. 2b), implicating a direct role of HA on vessel formation.

\section{Elevated expression of pro-angiogenic factors in endothelial cells upon HA treatment}

Liver sinusoidal endothelial cells (LSECs) act as a filter between the lumen of the hepatic sinusoids and the surrounding hepatocytes. These sinusoidal endothelial fenestrations are altered by various liver diseases, diabetes mellitus and old age due to the influence of cytokines and hormones [39]. The various agents that influence the number and diameter of fenestrations are 


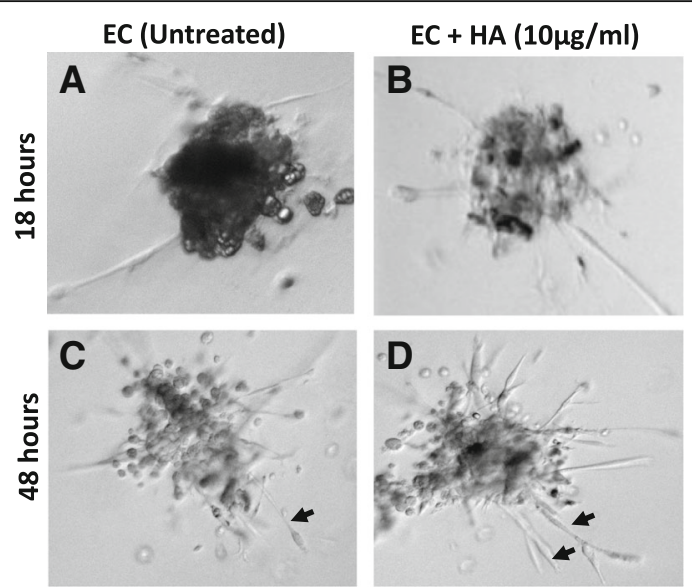

E

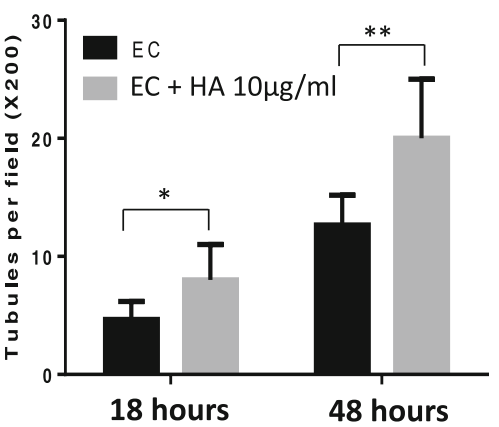

Fig. 2 Effect of HA treatment on tubule formation of ECs. The influence of HA on vascular tubule formation of ECs are shown with DIC images of Matrigel assay. Murine ECs with HA treatment (right panel) were found with more growing vascular sprouts in comparison to untreated ECs (left panel) after $18 \mathrm{~h}(\mathbf{a}, \mathbf{b})$ and $48 \mathrm{~h}(\mathbf{c}, \mathbf{d})$ respectively. e The quantification of tubules (indicated with arrows) were measured per microscopic field after indicated time points. ${ }^{*} p<0.05 ;{ }^{* *} p<0.01$

calcium, serotonin, ethanol, prostaglandins, endothelin-1 etc. [40, 41]. But recent reports imply an immense influence of vascular endothelial growth factor (VEGF) on genesis of fenestrations [42]. During this process hepatocytes exhibit molecular heterogeneity based on their location within the hepatic lobule or hepatic zonation [43]. $\beta$-catenin is one of the key molecules regulating the zonation pattern. It is required for expansion of hepatoblasts during early stages of hepatic morphogenesis and for proper specification of hepatoblasts as well as hepatocyte maturation during later stages. $\beta$-catenin regulates the expression of genes such as glutamine synthetase (GS) and certain cytochrome P450 enzymes (CYPs), such as Cyp1a2 and Cyp2e1 [44]. In addition, $\beta$-catenin signalling is also essential for the initiation of liver regeneration (LR).

To understand whether HA mediates angiogenesis by up-regulation of these key angiogenic factors, we subsequently estimated both the mRNA as well as protein levels of VEGF-A, VEGFR1 and $\beta$-catenin in whole cell lysates of HA treated and untreated ECs. Elevated mRNA levels of typical angiogenic growth factors like VEGFR1, VEGF-A, $\beta$-catenin (Fig. 3a) have been
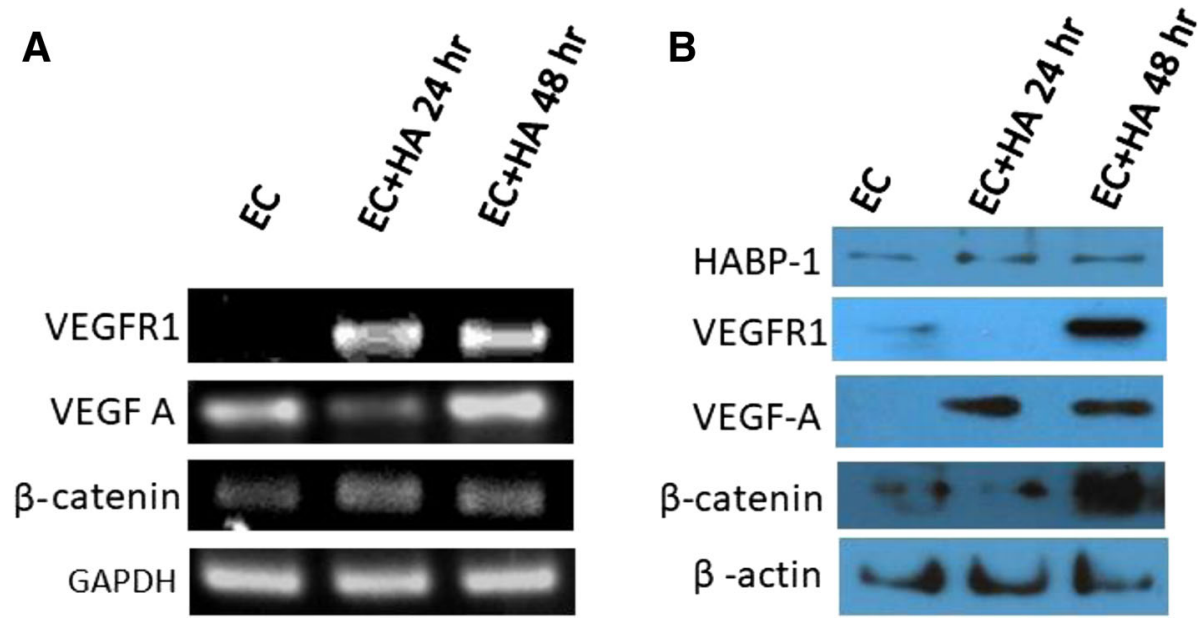

Fig. $3 \mathrm{HA}$ treatment up-regulates pro angiogenic factors within ECs. a Reverse transcriptase PCR with VEGFR1, VEGFA and $\beta$ - catenin primers confirmed increased mRNA level in murine ECs upon HA treatment at mentioned time points. b Immunoblot with anti-HABP1, anti- VEGFR1, anti- VEGFA and anti- $\beta$-catenin antibody showed increased VEGFR1, VEGFA and $\beta$ - catenin protein levels after HA treatment of 24 and 48 h. Equal protein loading is confirmed by probing the blot with $\beta$-actin antibody 
observed in ECs upon HA treatment. Immunoblotting with $\beta$-catenin, VEGF-A and VEGFR1 antibodies also elucidated augmented protein expression of VEGF-A, VEGFR1, $\beta$-catenin and a little elevation in HABP1 level in HA treated ECs as compared to the untreated ECs (Fig. 3b). Quantitative PCR (qPCR) analysis for mRNA expression level of crucial regulators of angiogenic pathway demonstrated a significant up-regulation of VEGFA ( 3.2 fold) and a huge increase in VEGFR1 mRNA ( 9.5 fold) level (Fig. 4a). A relative increase in the mRNA level of HABP1 ( 6.5 fold) and $\beta$-catenin $(\sim 4.2$ fold $)$ has also been observed in the HA treated ECs. Among the three principal cell surface receptors for HA, only VECAM (Vascular Endothelial Cell Adhesion Molecule) mRNA was augmented in HA treated ECs (after $48 \mathrm{~h}$ of treatment) as compared to the untreated ECs. But, no significant change was observed for mRNA levels of RHAMM (Receptor for Hyaluronan Mediated Motility) (Fig. 4b-c). Although no change in the overall mRNA level of NF-kB1 (p50 subunit of $\mathrm{NF}-\kappa \mathrm{B})$ has been observed upon HA treatment but a significant increase in transcription factor p65 (nuclear factor NF-kB, p65 subunit) which is very crucial for nuclear translocation and NF- $\mathrm{kB}$ signalling (Fig. 4d).

\section{Alterations in F-actin distribution and differential} localization of HABP1 and $\beta$-catenin upon HA treatment in ECs

Apart from its role in angiogenesis, VEGF is also required for a tight regulation of the contractile and non-contractile states of actin cytoskeletal organization. It is also believed that the orientation of the cytoskeleton inside the cells can control the orientation of the matrix produced outside. The cytoskeletal integrity of the HA treated and untreated ECs was studied here by observing the expression profile of F-actin. The actin network (red) were labelled with fluorophore-conjugated phalloidin (Fig. 5a \& d) and the nuclei (blue) were labelled with Hoechst 33342 (Fig. 5b \& e). Rhodamine-phalloidin staining indicated significantly altered distribution of F-actin in the HA treated ECs as compared to control untreated ECs (Fig. 5c). Increased fluorescence intensity of phalloidin (Fig. 5d \& f) indicates that the exposure of murine sinusoidal ECs with HA promotes polymerization and reorganization of F-actin. Previous studies have revealed dynamic subcellular localization of the hyaladherin, HABP1 [45]. Thus, presuming a role of HA supplementation on the sub-cellular localization pattern of HABP1 in the ECs, immunofluorescence studies were performed
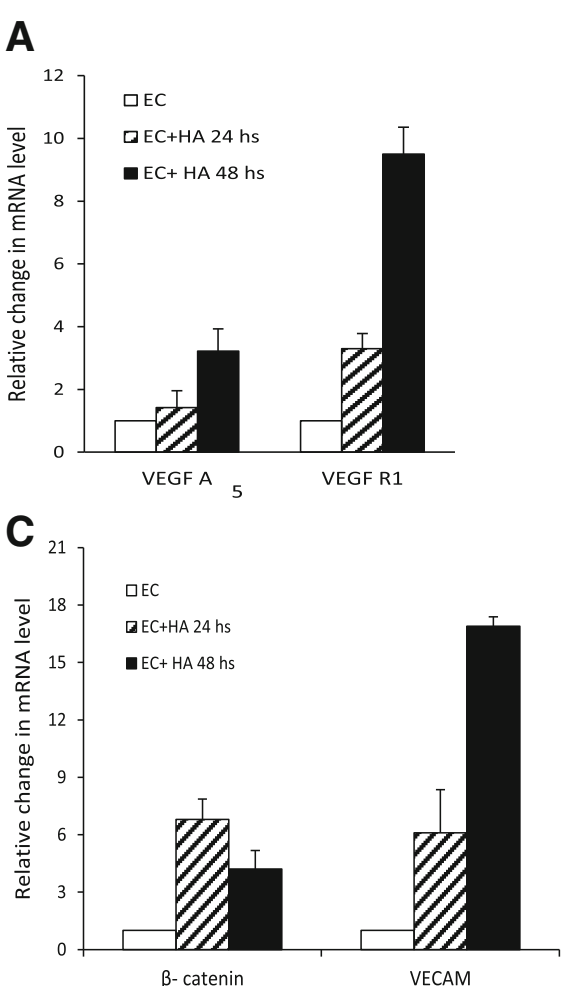

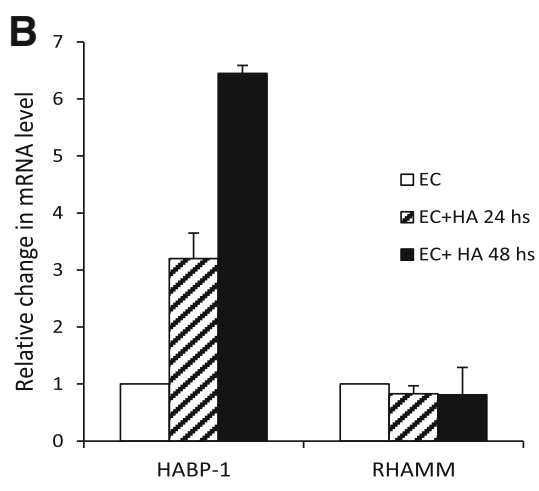

D

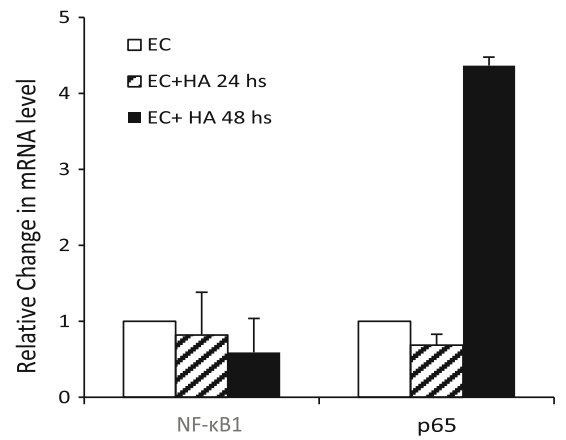

Fig. 4 Alteration in mRNA expression of angiogenic factors in ECs upon HA treatment. Real-time PCR showing the relative fold change in mRNA level of several pro-angiogenic factors like a VEGF (Vascular endothelial growth factor) and VEGFR1 (Vascular endothelial growth factor receptor 1), b HABP1 (Hyaluronic acid binding protein1) and RHAMM (Hyaluronan mediated motility receptor) c $\beta$-catenin (Catenin $\beta 1$ ) and VECAM (Vascular cell adhesion molecule) d NF-kB1 (p50 subunit of nuclear factor kappa-light-chain-enhancer of activated B cells) and p65 (nuclear factor NF-kappa-B p65 subunit) 

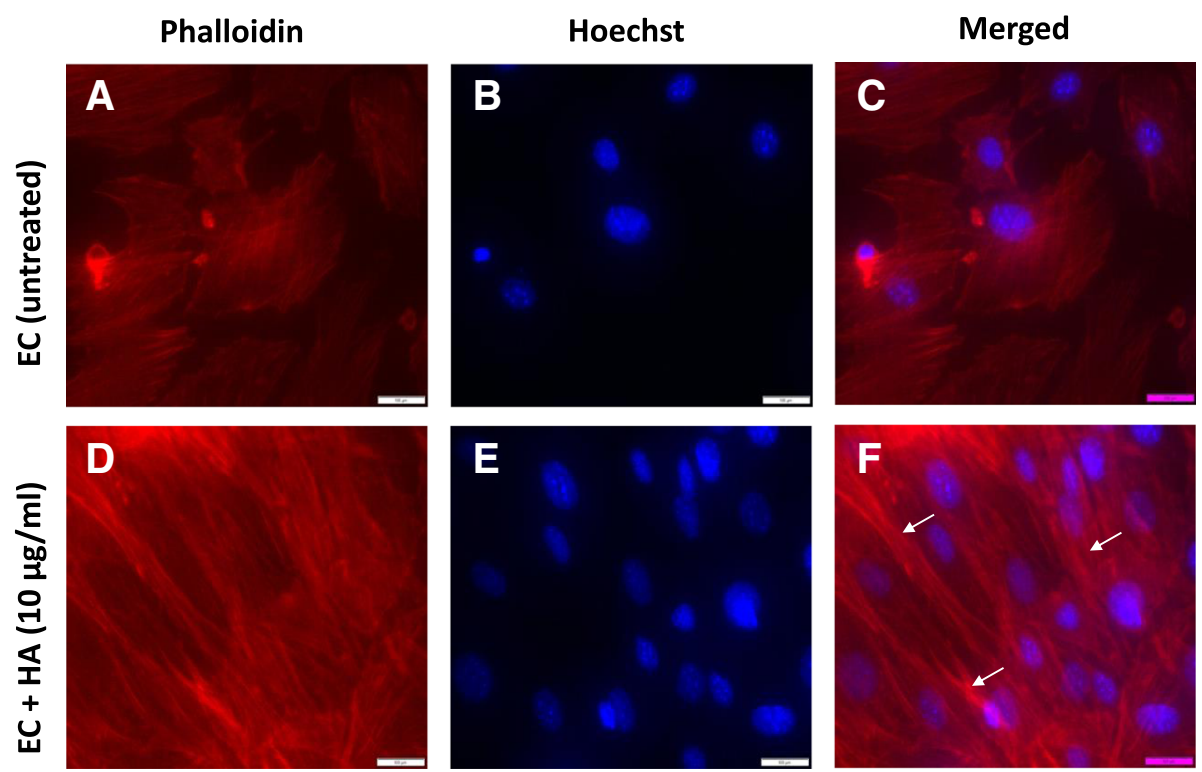

Fig. 5 HA induces morphological and cytoskeletal alterations in ECs. a, d Cells were stained with Phalloidin to detect F-actin, (b, e) stained with Hoechst and (c, f) showing merged picture of phalloidin and Hoechst of untreated ECs (upper panel) vs HA treated (10 $\mathrm{\mu g} / \mathrm{ml})$ ECs for $48 \mathrm{~h}$ (lower panel). The higher fluorescence intensity of phalloidin in ECs were indicated with arrows. Scale bar, $20 \mu \mathrm{m}$

using anti-HABP1 antibody in both the treated and untreated ECs. Fluorescence microscopy revealed mostly nuclear or perinuclear localization of HABP1 in the untreated ECs, while HA treated ECs showed a higher expression of HABP1 though out the cells, indicating a possible translocation of HABP1 from the nuclear periphery to the surface. Moreover, the immunofluorescence studies also indicated elevated levels of HABP1 in HA treated liver ECs as compared to untreated ones (Fig. 6a). During the course of our subcellular localization studies, $\beta$ - catenin was detected at the cellular periphery in the untreated murine ECs. On the contrary, HA treatment of ECs led to internalization of $\beta$ - catenin to the nucleus as it was observed mostly to be co-localized with Hoechst stain, confirming nuclear localization (Fig. 6b).

\section{Discussion}

Serum HA levels reportedly increase during chronic liver diseases together with the development of liver fibrosis with different aetiologies including Hepatis B virus (HBV), Hepatitis $\mathrm{C}$ virus (HCV) infection or alcoholic damage [46]. Initially, enhancement of HA production by the activated stellate cells may contribute to the increase in serum HA levels observed in patients with chronic liver disease without cirrhosis, including primary biliary cirrhosis [47] or chronic hepatitis $C[16,48]$. Later, when cirrhosis is established, reduced degradation by LSEC may result in HA accumulation $[16,47]$. The development of hepatic sinusoid capillarization might be able to explain the reduced HA degradation. In spite of the fact, that several studies have described serum HA as a fibrosis marker in Chronic Hepatitic C [49-53], but still there are reservations to include $\mathrm{HA}$ as a non-invasive marker for diagnosis of chronic HBV patients [54-57]. It is evident from clinical data, that in patients with cirrhosis and high serum HA levels are clearly associated with clinical severity, the occurrence of complications or death [58-60]. Serum HA levels are also shown to be related to the effect of interferon- $\alpha$ therapy on liver fibrosis $[16,61]$. Therefore, it is important to understand the influence of $\mathrm{HA}$ in the cellular components of liver especially liver ECs.

ECs contain unusually high amounts of endocytic vesicles, which suggests their engagement in uptake of proteins from blood passing through the sinusoids [26]. Most interestingly the first physiological macromolecule shown to be cleared from the circulation by ECs is HA $[62,63]$. Co-ordinated functional role of HA and HABP1 in liver ECs in term of angiogenesis tempted us to understand the therapeutic implications of ECs. Previous reports elucidated the fact, that overexpression of HABP1 in the human liver cell line HepG2, induces higher endogenous HA level and inter-cellular HA cables, glutathione levels and enhanced cellular proliferation over longer periods of cell growth. Enhanced levels of hyaluronan synthase 2 (HAS2) and CD44, a receptor of HA has also been reported in the same study. The elevated level of HABP1 thus, leads to enhanced tumorigenic potential of the hepatocarcinoma cells, by HA mediated pathways with upregulation of AKT, $p$-AKT, $\beta$-catenin and cyclinD1 [10]. The cell surface expressed form of HABP1 has been predicted as a new biomarker 

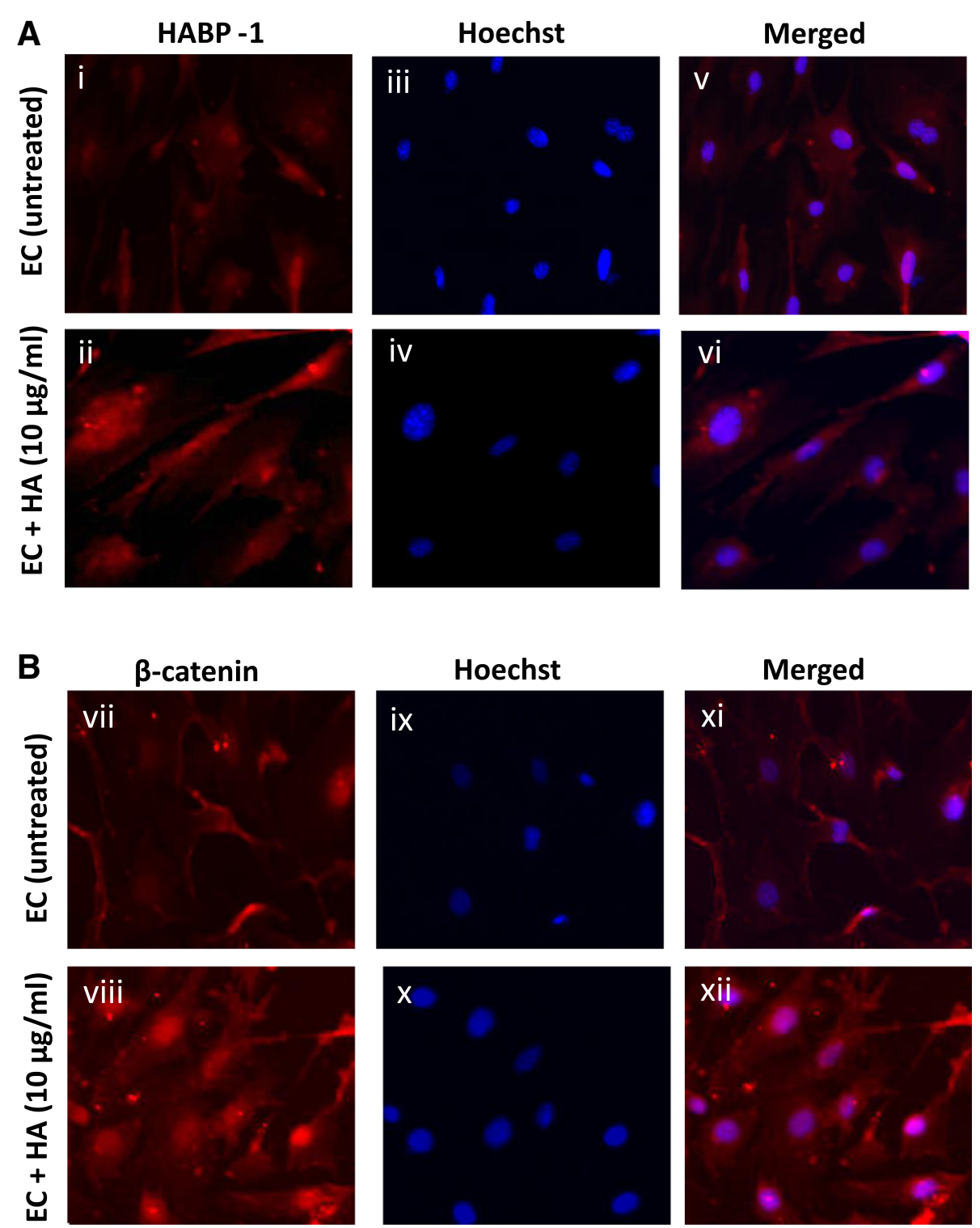

Fig. $6 \mathrm{HA}$ treatment influences localization of HABP1 and $\beta$-catenin in ECs. a Immunofluorescence staining showed cellular localization of endogenous HABP1 in mouse liver ECs, without HA treatment and with HA treatment. (i, ii) showing localization of HABP1, (iii, iv) staining with hoechst for detecting nucleus and $(\mathrm{v}, \mathrm{vi})$ merged picture of HABP1 and hoechst. b Cellular localization of endogenous $\beta$-catenin in mouse liver ECs, without HA treatment and with HA treatment. (vii, viii) showing localization of $\beta$-catenin, (ix, $x$ ) staining with hoechst for detecting nucleus and $(x i, x i i)$ merged picture of $\beta$-catenin and hoechst

of tumor cells and tumor associated macrophages in metabolically deprived or hypoxic areas of tumor [64]. In the present study, our findings have suggested exogenous administration of HA accompanied by elevated levels of HABP1 and complete dispersion throughout the cell might have a crucial impact in inducing cellular proliferation and enhanced adhesion as well as cell migration in ECs. The diverse subcellular localization of HABP1 upon HA treatment suggest that it could be a component of the trafficking pathway connecting the nucleus, mitochondria and cytoplasm and the export pathway to the cell surface (Fig. 7). Upon examining the pro-angiogenic action of $\mathrm{HA}$ and and its effect on angiogenesis, it has been revealed that even HA supplementation in the media is sufficient enough to promote vessel formation and confer a pro-angiogenic phenotype to endothelial cells in vitro. Very recent studies have interpreted the crucial events on interactions of HA with its cellular receptor $\mathrm{CD} 44$ regulating the progression of tumor $[65,66]$. In fact matrix HA endorses specific microRNA, which leads to drug resistance apart from influencing tumor progression. MicroRNAs reportedly 


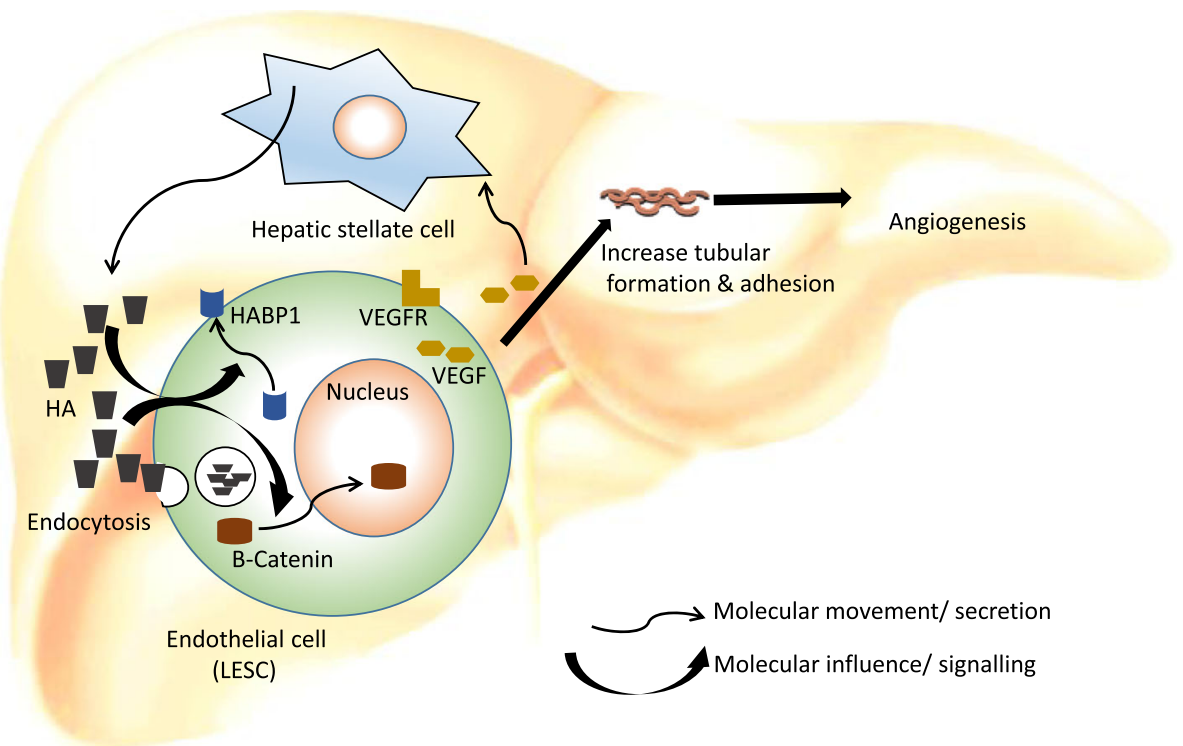

Fig. 7 Schematic diagram showing influence of HA on angiogenesis in liver ECs. In the liver microenvironment the sinusoidal pericyte, hepatic stellate cells (HSCs) synthesize HA and this compound degraded by the sinusoidal ECs via the process of endocytosis [16]. Elevated HA level or administration of HA are co-ordinate with expression of HABP1 and internalization of $\beta$-catenin in ECs. HA treatment enhanced the tubular sprout formation, rearrangement of the actin cytoskeleton, cell migration and adhesion along with overexpression of angiogenic factors VEGFA and VEGFR1 in liver ECs

regulate the post-translational modifications of HA synthases (HASes) which impacts the HA synthesis and secretion in the tumor microenvironment $[65,67]$.

In this context, VEGF and its receptor, VEGFR1 are most vital factors during angiogenesis, having a central role in EC proliferation. Our work confirmed the overexpression of these potent angiogenic factors, VEGFA and VEGFR1 upon HA treatment both at the transcript and protein levels $[2,3]$. Here, we confirmed the effect of soluble HA upon the rearrangement of the actin cytoskeletal. Thus, HA-mediated signalling pathways are likely to regulate actin cytoskeletal organization and cell migration. Among multiple pathways that have been reported to participate in the regulation of tumor angiogenesis and metastasis, Wnt/ß-catenin signalling pathways contribute to hepatocellular carcinoma. Increased levels of HA are reported to induce cell survival pathway via the activation of AKT and $\beta$ - catenin $[10,68]$. On the other hand, $\beta$-catenin pathway has also been reported to regulate the expression of VEGF in colorectal cancer [34]. Canonical Wnt/ $\beta$-catenin signalling regulates gene transcription by enabling translocation of $\beta$-catenin from the cytoplasm into the nucleus [33]. In our experimental system, we not only observed upregulation of $\beta$-catenin expression, but also detected the nuclear translocation of the protein from the membrane upon HA treatment (Fig. 7). Furthermore, nuclear factor, NF- $\mathrm{kB}$ is pivotal in the regulation of many genes including adhesion molecules. Recent studies imply that, phosphorylation and degradation of
$\mathrm{I} \kappa \mathrm{B}$ is not enough for NF- $\mathrm{BB}$ dependent transcription. Phosphorylation of p65 subunit of NF-kB or RelA can also activate NF-kB-dependent transcription [69, 70]. In fact, earlier studies from the lab revealed HABP1 induced migration of melanoma cells, as well as tumor growth by NF-kB dependent MMP-2 activation [69]. Since HA treated ECs have been found to be more adhesive in nature, we analysed the transcript levels of p65 subunit of NF- $\mathrm{kB}$ along with the NF- $\mathrm{kB} 1$ (p50 subunit). Although HA treatment did not influence the mRNA levels of NF-kB1, but a highly elevated mRNA level of p65 subunit of NF- $\mathrm{KB}$ has been elucidated from the study. This observation relegates a critical question for future studies to determine how these pathways interact to facilitate angiogenesis.

\section{Conclusions}

Our study has shed light on five major piece of evidence; HA mediated signaling in liver ECs increases i) proliferation, migration and adhesion ii) tubular formation and alteration in cytoskeletal organization iii) expression of pro-angiogenic factors iv) dispersion and recruitment of HABP1 towards cellular membrane to influence HA mediated signaling $\mathrm{v}$ ) mobilization of $\beta$-catenin to nucleus for transcriptional activation of angiogenesis. The elucidation of the molecular mechanisms regulating HA-mediated cellular signalling in ECs will not only contribute greatly to our understanding of cancer progression but will also offer many new avenues of therapeutic intervention. ECs should 
be considered as an attractive model for future and existing anti-angiogenic strategies directed against the stromal compartment of liver metastases.

\section{Additional file}

Additional file 1: Table S1. Sequences of primers used for quantitative real time PCR on mice. (DOCX $25 \mathrm{~kb}$ )

\section{Abbreviations}

EC: Endothelial cells; GAPDH: Glyceraldehyde-3-phosphate dehydrogenase; HA: Hyaluronic acid or Hyaluronan; HABP1: Hyaluronic acid binding protein1; NF-kB: Nuclear factor kappa-light-chain-enhancer of activated B; RHAMM: Receptor for hyaluronan mediated motility; VECAM: Vascular endothelial cell adhesion molecule; VEGFA: Vascular endothelial growth factor A; VEGFR1: Vascular endothelial growth factor receptor 1

\section{Acknowledgements}

We would like to thank Prof. Chinmay K Mukhopadhyay from Jawaharlal Nehru University (JNU), New Delhi, India, Prof. Gopal Kundu from National Centre for Cell Science (NCCS), Pune, India and Prof. Bhudev C Das, Amity Institute of Molecular Medicine and Stem Cell Research, Noida, India for their valuable suggestions.

\section{Funding}

Authors are grateful for support from Council of Scientific and Industrial research [13(8600-A)/2012-Pool to SG as PI], Science and Engineering Research Board (SERB), Department of Science and Technology, India (YSS/ 2015/000092 to SG as PI) and Department of Biotechnology, India (BT/ PR15011/MED/30/1578/2015 to SB as PI) to pursue this study.

\section{Availability of data and materials}

The data generated and or analysed in this studies are included in this articles.

\section{Authors' contributions}

SG performed most experiments. SG and SB wrote the paper, critically analysed experiments and data. KD and RK contributed in writing, examining and supporting the research investigations. All authors read and approved the final manuscript.

\section{Ethics approval and consent to participate}

Our study (IEC-244/05.05.2017) is carried out as per direction by Institute Ethics committee, All India Institute of Medical Sciences, New Delhi, India.

\section{Consent for publication}

Authors certify that no portion of this manuscript has been previously published.

\section{Competing interests}

The authors declare that they have no competing interests.

\section{Publisher's Note}

Springer Nature remains neutral with regard to jurisdictional claims in published maps and institutional affiliations.

\section{Author details}

'Department of Medical Oncology, All India Institute of Medical Sciences, Ansari Nagar, New Delhi 110029, India. ${ }^{2}$ Special Centre for Molecular Medicine, Jawaharlal Nehru University, New Delhi, India. ${ }^{3}$ Amity Institute of Molecular Medicine and Stem Cell Research, Amity University Uttar Pradesh (AUUP), Sector 125, NOIDA, Uttar Pradesh 201313, India. ${ }^{4}$ School of Environmental Sciences, Jawaharlal Nehru University, New Delhi, India.
Received: 15 November 2017 Accepted: 18 May 2018

Published online: 11 June 2018

\section{References}

1. Rahmanian M, Pertoft H, Kanda S, Christofferson R, Claesson-Welsh L, Heldin P. Hyaluronan oligosaccharides induce tube formation of a brain endothelial cell line in vitro. Exp Cell Res. 1997:237(1):223-30.

2. Rousseau S, Houle F, Huot J. Integrating the VEGF signals leading to actinbased motility in vascular endothelial cells. Trends Cardiovasc. Med. 2000; 10(8):321-7.

3. Rousseau S, Houle F, Kotanides H, Witte L, Waltenberger J, Landry J, Huot J. Vascular endothelial growth factor (VEGF)-driven actin-based motility is mediated by VEGFR2 and requires concerted activation of stress-activated protein kinase 2 (SAPK2/p38) and geldanamycin-sensitive phosphorylation of focal adhesion kinase. J Biol Chem. 2000;275(14):10661-72.

4. Fjeldstad K, Kolset SO. Decreasing the metastatic potential in cancerstargeting the heparan sulfate proteoglycans. Curr Drug Targets. 2005;6(6): $665-82$.

5. Jaffe EA, Nachman RL, Becker CG, Minick CR. Culture of human endothelial cells derived from umbilical veins. Identification by morphologic and immunologic criteria. J Clin Invest. 1973;52(11):2745-56.

6. Wu M, Du Y, Liu Y, He Y, Yang C, Wang W, Gao F. Low molecular weight hyaluronan induces lymphangiogenesis through LYE-1-mediated signaling pathways. PLoS One. 2014:9(3):e92857.

7. Gupta S, Datta K. Possible role of hyaluronectin on cell adhesion in rat histiocytoma. Exp Cell Res. 1991;195(2):386-94.

8. D'Souza M, Datta K. Evidence for naturally occurring hyaluronic acid binding protein in rat liver. Biochem Int. 1985;10(1):43-51.

9. Saha P, Datta K. Multi-functional, multicompartmental hyaluronan-binding protein 1 (HABP1/p32/gC1qR): implication in cancer progression and metastasis. Oncotarget. 2018;9(12):10784-807.

10. Kaul R, Saha P, Saradhi M, Prasad RL, Chatterjee S, Ghosh I, Tyagi RK, Datta K Overexpression of hyaluronan-binding protein 1 (HABP1/p32/gC1qR) in HepG2 cells leads to increased hyaluronan synthesis and cell proliferation by up-regulation of cyclin D1 in AKT-dependent pathway. J Biol Chem. 2012;287(23):19750-64

11. Meenakshi J, Anupama Q, Goswami SK, Datta K. Constitutive expression of hyaluronan binding protein 1 (HABP1/p32/gC1qR) in normal fibroblast cells perturbs its growth characteristics and induces apoptosis. Biochem Biophys Res Commun. 2003;300(3):686-93.

12. Chowdhury AR, Ghosh I, Datta K. Excessive reactive oxygen species induces apoptosis in fibroblasts: role of mitochondrially accumulated hyaluronic acid binding protein 1 (HABP1/p32/gC1qR). Exp Cell Res. 2008;314(3):651-67.

13. Itano N, Atsumi F, Sawai T, Yamada Y, Miyaishi O, Senga T, Hamaguchi M, Kimata K. Abnormal accumulation of hyaluronan matrix diminishes contact inhibition of cell growth and promotes cell migration. Proc Natl Acad Sci U S A. 2002;99(6):3609-14.

14. Stern R. Hyaluronidases in cancer biology. Semin Cancer Biol. 2008;18(4): $275-80$.

15. Genasetti A, Vigetti D, Viola M, Karousou E, Moretto P, Rizzi M, Bartolini B, Clerici M, Pallotti F, De Luca G, et al. Hyaluronan and human endothelial cell behavior. Connect Tissue Res. 2008:49(3):120-3.

16. Guechot J, Poupon RE, Giral P, Balkau B, Giboudeau J, Poupon R. Relationship between procollagen III aminoterminal propeptide and hyaluronan serum levels and histological fibrosis in primary biliary cirrhosis and chronic viral hepatitis C. J Hepatol. 1994:20(3):388-93.

17. Yang J, Mowry LE, Nejak-Bowen KN, Okabe H, Diegel CR, Lang RA, Williams $\mathrm{BO}$, Monga SP. Beta-catenin signaling in murine liver zonation and regeneration: a Wnt-Wnt situation! Hepatology. 2014;60(3):964-76.

18. Lade AG, Monga SP. Beta-catenin signaling in hepatic development and progenitors: which way does the WNT blow? Dev Dyn. 2011;240(3):486-500

19. Han SA, Chun H, Park CM, Kang SJ, Kim SH, Sohn D, Yun SH, Lee WY. Prognostic significance of beta-catenin in colorectal cancer with liver metastasis. Clin Oncol (R Coll Radiol). 2006;18(10):761-7.

20. Zhang N, Wei P, Gong A, Chiu WT, Lee HT, Colman H, Huang H, Xue J, Liu $M$, Wang $Y$, et al. FoxM1 promotes beta-catenin nuclear localization and controls Wnt target-gene expression and glioma tumorigenesis. Cancer Cell. 2011;20(4):427-42

21. Schrage A, Loddenkemper C, Erben U, Lauer U, Hausdorf G, Jungblut PR, Johnson J, Knolle PA, Zeitz M, Hamann A, et al. Murine CD146 is widely 
expressed on endothelial cells and is recognized by the monoclonal antibody ME-9F1. Histochem Cell Biol. 2008;129(4):441-51.

22. Maharjan AS, Pilling D, Gomer RH. High and low molecular weight hyaluronic acid differentially regulate human fibrocyte differentiation. PLoS One. 2011;6(10):e26078.

23. Saha P, Ghosh I, Datta K. Increased hyaluronan levels in HABP1/p32/gC1qR overexpressing HepG2 cells inhibit autophagic vacuolation regulating tumor potency. PLoS One. 2014;9(7):e103208.

24. Gressner AM, Schafer S. Comparison of sulphated glycosaminoglycan and hyaluronate synthesis and secretion in cultured hepatocytes, fat storing cells, and Kupffer cells. J Clin Chem Clin Biochem. 1989;27(3):141-9.

25. Gressner AM, Bachem MG. Cellular sources of noncollagenous matrix proteins: role of fat-storing cells in fibrogenesis. Semin Liver Dis. 1990; 10(1):30-46

26. Eriksson S, Fraser JR, Laurent TC, Pertoft H, Smedsrod B. Endothelial cells are a site of uptake and degradation of hyaluronic acid in the liver. Exp Cell Res. 1983;144(1):223-8

27. Fraser JR, Alcorn D, Laurent TC, Robinson AD, Ryan GB. Uptake of circulating hyaluronic acid by the rat liver. Cellular localization in situ. Cell Tissue Res. 1985;242(3):505-10.

28. Frost SJ, Raja $\mathrm{RH}$, Weigel $\mathrm{PH}$. Characterization of an intracellular hyaluronic acid binding site in isolated rat hepatocytes. Biochemistry. 1990;29(45): 10425-32.

29. Alston-Smith J, Pertoft H, Laurent TC. Endocytosis of hyaluronan in rat Kupffer cells. Biochem J. 1992;286(Pt 2):519-26.

30. Meng D. Response to letter by Loboda et al regarding article, "Bach1 represses Wnt/beta-catenin signaling and angiogenesis". Circ Res. 2015;117(9):e77-8.

31. Loboda A, Florczyk U, Jazwa A, Grochot-Przeczek A, Nowak W, Jozkowicz A, Dulak J. Letter by Loboda et al regarding article, "Bach1 represses Wnt/betacatenin signaling and angiogenesis": IL-8 is not present in murine genome hence it cannot be responsible for the Bach1 effect on angiogenesis in mice. Circ Res. 2015;117(9):e75-6.

32. Sanz-Cameno P, Trapero-Marugan M, Chaparro M, Jones EA, Moreno-Otero R. Angiogenesis: from chronic liver inflammation to hepatocellular carcinoma. J Oncol. 2010;2010:272170.

33. Jiang L, Yin M, Wei X, Liu J, Wang X, Niu C, Kang X, Xu J, Zhou Z, Sun S, et al. Bach1 represses Wnt/beta-catenin signaling and angiogenesis. Circ Res. 2015:117(4):364-75.

34. Calviello G, Resci F, Serini S, Piccioni E, Toesca A, Boninsegna A, Monego G, Ranelletti FO, Palozza P. Docosahexaenoic acid induces proteasomedependent degradation of beta-catenin, down-regulation of survivin and apoptosis in human colorectal cancer cells not expressing COX-2. Carcinogenesis. 2007;28(6):1202-9.

35. Iwakiri Y, Groszmann RJ. Vascular endothelial dysfunction in cirrhosis. J Hepatol. 2007:46(5):927-34.

36. Shah V. Cellular and molecular basis of portal hypertension. Clin Liver Dis. 2001:5(3):629-44.

37. Yang ZF, Poon RT. Vascular changes in hepatocellular carcinoma. Anat Rec (Hoboken). 2008;291(6):721-34

38. O'Reilly JN, Cogger VC, Le Couteur DG. Old age is associated with ultrastructural changes in isolated rat liver sinusoidal endothelial cells. J Electron Microsc. 2010;59(1):65-9.

39. Hilmer SN, Cogger VC, Fraser R, McLean AJ, Sullivan D, Le Couteur DG. Agerelated changes in the hepatic sinusoidal endothelium impede lipoprotein transfer in the rat. Hepatology. 2005;42(6):1349-54

40. Arias IM. The biology of hepatic endothelial cell fenestrae. Prog Liver Dis. 1990;9:11-26

41. Jamieson HA, Hilmer SN, Cogger VC, Warren A, Cheluvappa R, Abernethy $D R$, Everitt AV, Fraser R, de Cabo R, Le Couteur DG. Caloric restriction reduces age-related pseudocapillarization of the hepatic sinusoid. Exp Gerontol. 2007:42(4):374-8.

42. Yokomori H, Oda M, Yoshimura K, Nagai T, Ogi M, Nomura M, Ishii H. Vascular endothelial growth factor increases fenestral permeability in hepatic sinusoidal endothelial cells. Liver International. 2003;23(6):467-75.

43. Gebhardt R, Matz-Soja M. Liver zonation: novel aspects of its regulation and its impact on homeostasis. World J Gastroenterol. 2014;20(26):8491-504.

44. Monga SP. Role of Wnt/beta-catenin signaling in liver metabolism and cancer. Int J Biochem Cell Biol. 2011;43(7):1021-9.

45. Sengupta A, Banerjee B, Tyagi RK, Datta K. Golgi localization and dynamics of hyaluronan binding protein 1 (HABP1/p32/C1QBP) during the cell cycle. Cell Res. 2005;15(3):183-6.
46. Ichida T, Sugitani S, Satoh T, Matsuda Y, Sugiyama M, Yonekura K, Ishikawa T, Asakura H. Localization of hyaluronan in human liver sinusoids: a histochemical study using hyaluronan-binding protein. Liver. 1996;16(6):365-71.

47. Nyberg A, Engstrom-Laurent A, Loof L. Serum hyaluronate in primary biliary cirrhosis-a biochemical marker for progressive liver damage. Hepatology. 1988:8(1):142-6.

48. Murawaki $Y$, Ikuta $Y$, Koda M, Nishimura $Y$, Kawasaki $H$. Clinical significance of serum hyaluronan in patients with chronic viral liver disease. J Gastroenterol Hepatol. 1996;11(5):459-65.

49. Fontana RJ, Lok AS. Noninvasive monitoring of patients with chronic hepatitis C. Hepatology. 2002;36(5 Suppl 1):S57-64.

50. Attallah AM, Toson el SA, El-Waseef AM, Abo-Seif MA, Omran MM, Shiha GE. Discriminant function based on hyaluronic acid and its degrading enzymes and degradation products for differentiating cirrhotic from non-cirrhotic liver diseased patients in chronic HCV infection. Clin Chim Acta. 2006;369(1): $66-72$.

51. Esmat G, Metwally M, Zalata KR, Gadalla S, Abdel-Hamid M, Abouzied A Shaheen AA, El-Raziky M, Khatab H, El-Kafrawy S, et al. Evaluation of serum biomarkers of fibrosis and injury in Egyptian patients with chronic hepatitis C. J Hepatol. 2007;46(4):620-7.

52. Halfon P, Bourliere M, Penaranda G, Deydier R, Renou C, Botta-Fridlund D, Tran A, Portal I, Allemand I, Rosenthal-Allieri A, et al. Accuracy of hyaluronic acid level for predicting liver fibrosis stages in patients with hepatitis $C$ virus. Comp Hepatol. 2005;4:6.

53. Mehta P, Ploutz-Snyder R, Nandi J, Rawlins SR, Sanderson SO, Levine RA. Diagnostic accuracy of serum hyaluronic acid, FIBROSpect II, and YKL-40 for discriminating fibrosis stages in chronic hepatitis C. Am J Gastroenterol. 2008;103(4):928-36

54. Cadranel JF, Rufat P, Degos F. Practices of liver biopsy in France: results of a prospective nationwide survey. For the Group of Epidemiology of the French Association for the Study of the liver (AFEF). Hepatology. 2000;32(3): 477-81.

55. Benlloch S, Berenguer M, Prieto M, Rayon JM, Aguilera V, Berenguer J. Prediction of fibrosis in HCV-infected liver transplant recipients with a simple noninvasive index. Liver Transpl. 2005;11(4):456-62.

56. Li HY, Dong Z, Ma H. Relationship between serum HBV DNA levels and serum hyaluronic acid levels in hepatitis B cirrhosis patients. Zhonghua Shi Yan He Lin Chuang Bing Du Xue Za Zhi. 2007;21(3):256-7.

57. Dong Z, Shen H, Zhang FK. Relationship between serum HBV DNA levels and hepatic fibrosis markers in chronic hepatitis B. Zhonghua Shi Yan He Lin Chuang Bing Du Xue Za Zhi. 2007;21(2):129-31.

58. Kropf J, Gressner AM, Tittor W. Logistic-regression model for assessing portal hypertension by measuring hyaluronic acid (hyaluronan) and laminin in serum. Clin Chem. 1991;37(1):30-5.

59. Gibson PR, Fraser JR, Brown TJ, Finch CF, Jones PA, Colman JC, Dudley FJ. Hemodynamic and liver function predictors of serum hyaluronan in alcoholic liver disease. Hepatology. 1992;15(6):1054-9.

60. Poupon RE, Balkau B, Guechot J, Heintzmann F. Predictive factors in ursodeoxycholic acid-treated patients with primary biliary cirrhosis: role of serum markers of connective tissue. Hepatology. 1994;19(3):635-40.

61. Ishibashi K, Kashiwagi T, Ito A, Tanaka Y, Nagasawa M, Toyama T, Ozaki S, Naito M, Azuma M. Changes in serum fibrogenesis markers during interferon therapy for chronic hepatitis type C. Hepatology. 1996;24(1):27-31.

62. Fraser JR, Pertoft H, Alston-Smith J, Laurent TC. Uptake of hyaluronan in hepatic endothelial cells is not directly affected by endotoxin and associated cytokines. Exp Cell Res. 1991;197(1):8-11.

63. Smedsrod B, Pertoft H, Eriksson S, Fraser JR, Laurent TC. Studies in vitro on the uptake and degradation of sodium hyaluronate in rat liver endothelial cells. Biochem J. 1984;223(3):617-26.

64. Fogal V, Zhang L, Krajewski S, Ruoslahti E. Mitochondrial/cell-surface protein p32/gC1qR as a molecular target in tumor cells and tumor stroma. Cancer Res. 2008;68(17):7210-8.

65. Karousou E, Misra S, Ghatak S, Dobra K, Gotte M, Vigetti D, Passi A, Karamanos NK, Skandalis SS. Roles and targeting of the HAS/hyaluronan/ CD44 molecular system in cancer. Matrix Biology. 2017:59:3-22.

66. Chen L, Bourguignon LY. Hyaluronan-CD44 interaction promotes c-Jun signaling and miRNA21 expression leading to BCl-2 expression and chemoresistance in breast cancer cells. Mol Cancer. 2014:13:52.

67. Bourguignon LY. Matrix Hyaluronan promotes specific MicroRNA upregulation leading to drug resistance and tumor progression. Int J Mol Sci. 2016;17(4):517 
68. Misra S, Obeid LM, Hannun YA, Minamisawa S, Berger FG, Markwald RR, Toole BP, Ghatak S. Hyaluronan constitutively regulates activation of COX-2mediated cell survival activity in intestinal epithelial and colon carcinoma cells. J Biol Chem. 2008:283(21):14335-44.

69. Prakash M, Kale S, Ghosh I, Kundu GC, Datta K. Hyaluronan-binding protein 1 (HABP1/p32/gC1qR) induces melanoma cell migration and tumor growth by NF-kappa B dependent MMP-2 activation through integrin alpha(v)beta(3) interaction. Cell Signal. 2011;23(10):1563-77.

70. Sabatel H, Di Valentin E, Gloire G, Dequiedt F, Piette J, Habraken Y. Phosphorylation of p65(RelA) on Ser(547) by ATM represses NF-kappaBdependent transcription of specific genes after genotoxic stress. PLoS One. 2012;7(6):e38246

Ready to submit your research? Choose BMC and benefit from:

- fast, convenient online submission

- thorough peer review by experienced researchers in your field

- rapid publication on acceptance

- support for research data, including large and complex data types

- gold Open Access which fosters wider collaboration and increased citations

- maximum visibility for your research: over $100 \mathrm{M}$ website views per year 